\title{
Differentiating Gilbert Syndrome from Crigler Najjar Syndrome Type 2 by Phenobarbitone Test
}

\author{
Sinha $\mathbf{R}^{1}$, Dalal $\mathbf{S}^{2}$, Sodhi $\mathrm{K}^{3}$
}

\begin{abstract}
Gilbert syndrome characterized by jaundice with intermittent elevations of indirect bilirubin, in the absence of haemolysis or underlying liver disease, has both autosomal dominant and recessive inheritance. Crigler-Najjar syndrome type II (CNS2) is a hereditary disorder of bilirubin metabolism characterized by unconjugated hyperbilirubinemia due to reduced and inducible activity of hepatic bilirubin glucuronosyltransferase (GT). We report 20 children between age 5 to 15 years with unconjugated hyperbilirubenemia who were given seven days of oral phenobarbitone $(5 \mathrm{mg} / \mathrm{kg} /$ day) and decrease in level of bilirubin was noted. There was only $30-40 \%$ reduction of bilirubin in Crigler Najjar Syndrome Type 2 compared to Gilberts Syndrome in which bilirubin level normalised. This case series highlights the importance of simple test to differentiate these two condition. This test is also very helpful in a place where enzyme level and mutational study cannot be done.
\end{abstract}

Key words: Gilberts, Crigler Najjar, Hyperbilirubinemia, Phenobarbitone

\section{Introduction}

G Ibert's syndrome is named after Augustin Gilbert (18581927), a French physician. It is defined as benign, familial, mild, unconjugated hyperbilirubinaemia not due to haemolysis and with normal routine tests of hepatic function and liver histology. The Crigler-Najjar syndrome type II (CNS2) is a hereditary disorder of bilirubin metabolism characterized by unconjugated hyperbilirubinemia due to reduced and inducible activity of hepatic bilirubin glucuronosyltransferase (GT). This study was conducted in a small town of Bhutan named Haa. The total population of Bhutan is around 7.5 lacs with Pediatric age group(1-15yrs) around 40\%.The population of Haa is around 12000 . We report 20 children between age 5 to 15 years with unconjugated hyperbilirubenemia who were given 7 days of oral phenobarbitone $(5 \mathrm{mg} / \mathrm{kg} /$ day) and decrease in level of bilirubin was noted.

\section{Material and Methods}

Twenty children of the age group 5-15 years were included in the study with a male to female ratio of $12: 8$. It was a prospective interventional study and 55 children were screened. The study was
'Dr. Rahul Sinha, MD, DNB Paediatrics, Military Hospital Jodhpur, ${ }^{2}$ Dr. Shamsher Dalal, MD, DM(Neonatology) Department of Paediatrics, AFMC Pune, India, ${ }^{3}$ Dr. Kirandeep Sodhi, MD, Department of Paediatrics, Command Hospital Chandigarh, India.

Address for correspondence:

Dr. Rahul Sinha

E-mail:drrahul_2000@yahoo.com

\section{How to cite}

Sinha R, Dalal S, Sodhi K. Differentiating Gilbert Syndrome from Crigler Najjar Syndrome Type 2 by Phenobarbitone Test. J Nepal Paediatr Soc 2015;35(1):82-84.

doi: http://dx.doi.org/10.3126/jnps.v35i1.10620

This work is licensed under a Creative Commons Attribution 3.0 License.

\section{(c) (i)}

conducted in a Government Hospital in Haa, Bhutan The entire panel of test for haemolytic disease, autoimmune disease and chronic liver disease were done and it was negative. Written informed consent of the parents were also taken. The permission of ethical committee was taken for the use of Phenobarbitone. The inclusion criteria were: Children between age group 5-15 years who have reported to our OPD from Oct 2012 to May 2014 with features of Jaundice and Unconjugated Hyperbilirubinemia (after blood testing) were included in the study. Exclusion criteria: Children with haemolytic disease and Conjugated Hyperbilirubenemia

Intervention: These 20 children were admitted and their baseline Total bilirubin (both conjugated and uncongugated), 
Enzymes SGOT/SGPT/ALP were recorded. The other causes of jaundice were ruled out by performing few tests. The Direct and indirect Coombs tests were negative. Serum haptoglobin, thyroid stimulating hormone, ceruloplasmin, ferritin, glucose-6-phosphate dehydrogenase, and alpha-1-antitrypsin levels, as well as a reticulocyte index were within normal limits. Serologic tests for hepatitis B and hepatitis $C$ showed no evidence of previous or active infection. Antinuclear antibody and antimitochondrial antibody tests were both negative. The detail clinical examination was done before Phenobarbitone administration. They were given oral Phenobarbitone $5 \mathrm{mg} / \mathrm{kg} /$ day for 7 days and levels of bilirubin including enzymes were recorded after 7 days and both reading were compared.

\section{Results}

It was Interventional prospective study in which levels of bilirubin and liver enzymes was checked before and after administration of Phenobarbitone. All the patients had undergone detail clinical examination before and after the intervention. The clinical examination was normal except for jaundice.

\section{Discussion}

Gilbert syndrome, found in $3 \%$ to $10 \%$ of the population, is the most common hereditary cause of increased bilirubin and is an autosomal recessive condition that is characterized by intermittent jaundice in the absence of hemolysis or underlying liver disease. Type 2 Crigler-Najjar syndrome (CNS2) is a hereditary disorder of bilirubin metabolism characterized by unconjugated hyperbilirubinemia due to reduced and inducible activity of hepatic bilirubin glucuronosyltransferase (GT). CNS2 is a milder form of CNS than CNS1. Numerous mutations in the UGT1A1 gene on 2 q37 are linked to CNS2 and result in reduced bilirubin GT activity, with marked impairment of bilirubin conjugation.

In our study 20 children were admitted for unconjugated hyperbilirubenemia evaluation in the age group 5-15 years. The only presenting feature was yellowish discolouration of eyes. The detail physical examination was done to rule out haemolytic/ chronic liver disease. There was scleral icterus in all the patient. The vital parameters were normal. There was no features of chronic liver disease. The liver span was

Table 1: List of all patients and the investigation results

\begin{tabular}{|c|c|c|c|c|c|c|c|}
\hline S No & Age Yrs & Sex & $\begin{array}{l}\text { Clinical Features } \\
\text { Icterus }\end{array}$ & $\begin{array}{l}\text { TB/UB } \\
\text { mg\% }\end{array}$ & $\begin{array}{l}\text { SGOT/SGPT/ALP } \\
\text { (Baseline) IU/L }\end{array}$ & $\begin{array}{c}\text { TB/UB (After } \\
\text { phenobarbitone) } \mathrm{mg} \%\end{array}$ & $\begin{array}{c}\text { Remarks } \\
\text { Likely Syndrome }\end{array}$ \\
\hline 1 & 6 & $M$ & + & $6 / 4$ & $30 / 40 / 86$ & $2 / 1.8$ & CNS 2 \\
\hline 2 & 5 & $\mathrm{~F}$ & + & $6 / 3.8$ & $25 / 35 / 100$ & $4 / 2.8$ & CNS 2 \\
\hline 3 & 8 & M & + & $5 / 3.5$ & $26 / 30 / 85$ & $3.5 / 2.5$ & CNS 2 \\
\hline 4 & 9 & $M$ & + & $4 / 3$ & $26 / 34 / 86$ & $1.2 / 0.8$ & GS \\
\hline 5 & 8 & $M$ & + & $6 / 4.5$ & $30 / 40 / 85$ & $1.5 / 0.9$ & GS \\
\hline 6 & 12 & $M$ & + & $6 / 4$ & $30 / 35 / 65$ & $1.5 / 0.9$ & GS \\
\hline 7 & 14 & $\mathrm{~F}$ & + & $6 / 4.8$ & $30 / 35 / 70$ & $4.5 / 3.5$ & CNS 2 \\
\hline 8 & 10 & $\mathrm{~F}$ & + & $8 / 6$ & $20 / 30 / 65$ & $1.5 / 0.9$ & GS \\
\hline 9 & 12 & M & + & $7 / 6$ & $35 / 30 / 68$ & $1.2 / 0.8$ & GS \\
\hline 10 & 15 & $\mathrm{~F}$ & + & $8 / 6.5$ & $28 / 25 / 80$ & $1.4 / 0.9$ & GS \\
\hline 11 & 11 & $\mathrm{~F}$ & + & $8 / 6.5$ & $35 / 40 / 68$ & $1.3 / 0.8$ & GS \\
\hline 12 & 12 & $\mathrm{~F}$ & + & $7 / 5.5$ & $35 / 45 / 65$ & $4.5 / 3.2$ & CNS 2 \\
\hline 13 & 6 & $M$ & + & $6 / 4.8$ & $35 / 40 / 100$ & $3.5 / 2.4$ & CNS 2 \\
\hline 14 & 7 & $M$ & + & $7 / 5.9$ & $38 / 22 / 110$ & $1.4 / 0.9$ & GS \\
\hline 15 & 8 & $M$ & + & $6 / 4.8$ & $40 / 42 / 96$ & $1.5 / 0.9$ & GS \\
\hline 16 & 9 & $M$ & + & $7.5 / 6$ & $36 / 40 / 90$ & $4.5 / 3.2$ & CNS 2 \\
\hline 17 & 5 & $M$ & + & $6.6 / 4$ & $35 / 40 / 100$ & $1.4 / 0.8$ & GS \\
\hline 18 & 7 & $M$ & + & $5.5 / 3.5$ & $28 / 35 / 85$ & $1.5 / 1.1$ & GS \\
\hline 19 & 12 & $\mathrm{~F}$ & + & $6 / 4.5$ & $40 / 45 / 100$ & $3.8 / 2.9$ & CNS 2 \\
\hline 20 & 15 & $\mathrm{~F}$ & + & $5 / 4$ & $24 / 36 / 86$ & $1.4 / 0.9$ & GS \\
\hline
\end{tabular}

CNS Crigler Najjar Syndrome 08

GS Gilbert Syndrome 12 
normal for age and there was no splenomegaly. The laboratory investigation revealed normal Complete blood count with normal peripheral blood smear. There was unconjugated hyperbilirunemia (Table 1) with mild elevation of liver enzymes. Subsequent laboratory testing revealed normal ranges of hemoglobin, lactate dehydrogenase, and transaminases. The other causes of jaundice were ruled out by relevant laboratory test as mentioned in the material and method section. The Ultrasonography revealed normal span with normal echotexture of liver in all the subjects. After phenobarbitone therapy there was normalising of bilirubin in 12 patients and $30-40 \%$ reduction in bilirubin in 8 patients. These 12 patients were likely to be suffering from Gilberts Syndrome and other 8 patients from Crigler Najjar syndrome 2. This high incidence of unconjugated hyperbilirubenemia in a small town of Bhutan could be most probably due to genetic cause.

A diagnosis of GS usually is made during or after puberty, possibly due to the inhibition of bilirubin glucuronidation by endogenous steroid hormones. In older individuals, the diagnosis usually is made when unconjugated hyperbilirubinemia is noted on routine blood tests or unmasked by an overlying illness. In the past, fasting; administration of nicotinic acid (IV), phenobarbital, or rifampin (rifampicin); and thin layer chromatography have been used to confirm a GS diagnosis. More recently, polymerase chain reaction testing has been used. A liver biopsy also can be performed but usually is not necessary ${ }^{4,5,6,7}$.

In our study Phenobarbitone test was used to differentiate Gilbert Syndrome and Crigler Najjar Syndrome. There are only very few studies of similar type in the literature. It is one of the most simple and cost effective test to differentiate these two condition. Also a larger study might be required to establish likely cause of unconjugated hyperbilirubinemia in this region.

\section{Conclusion}

This article highlights the importance of very simple test to differentiate these two rare syndrome without any side effects. This is very cheap and cost effective. In a resource constrained place this simple test is of prime importance to differentiate these two conditions. There is a need to conduct larger study to validate the higher incidence of unconjugated hyperbilirubinemia in paediatric age group.

\section{References}

1. Gilbert A, Lereboullet P. La cholamae simple familiale. Sem Med 1901;21:241-42.

2. Manandhar SR, Gurubacharya RL, Baral MR, Manandhar DS. A case report of Gilbert syndrome. Kathmandu Univ Med J 2003;1(3):187-89

3. Arias IM, Gartner LM, Cohen M, BenEzzer J, Levi AJ. Chronic non-hemolytic unconjugated hyperbilirubinemia with glucuronyl transferase deficiency. Am J Med 1969;47:395-409

4. Bosma PJ, Chowdhury JR, Bakker C, et al. The genetic basis of the reduced expression of bilirubin UDP-glucuronosyltransferase 1 in Gilbert's syndrome. N Engl J Med 1995;333(18):1171-175.

5. Kamisako T. What is Gilbert's syndrome? Lesson from genetic polymorphisms of UGT1A1 in Gilbert's syndrome from Asia. J Gastroenterol Hepatol. 2004;19(9):1023-28.

6. Hallal H, Egea JM, Mas P, García MD, PérezCuadrado E, Carballo F. A shortened, 2-hour rifampin test: A useful tool in Gilbert's syndrome. Gastroenterol Hepatol 2006;29(2):63-5.

7. Hunter JO, Thompson PH, Dunn PM, Williams R. Inheritance of Type 2 Crigler-Najjar Hyperbilirubinemia. Gut 1973;14:46-9. 